\title{
New border control system for food originating from third world countries
}

\author{
Matthias Heinzler ${ }^{1 *}$, Doris Gerlach ${ }^{2 \dagger}$, Hubertus Brunn ${ }^{3 \dagger}$
}

\begin{abstract}
Background: The global distribution of food products has created a requirement for inspection and testing of imported goods at national and outer European borders. Problems that are generally not encountered with local produce arise when dealing with imports from third world countries. These may include excessive levels of heavy metals, insufficient hygiene, unapproved veterinary pharmaceuticals in animal-derived foodstuffs or excessive levels of pesticides in plant products. The systematic control of imported food and feed is a challenging endeavour. Rigorous testing of imported non-animal food products by the Hesse State Laboratories was introduced in 2007 at Frankfurt/Main airport in order to protect German consumers from these potential health dangers. This ability to monitor imports with the entire personnel and analytical capacity of the Hesse State Laboratory is a new approach in governmental health inspection.
\end{abstract}

Results: From 2007 to 2009, a total of 1,552 food product samples of plant origin were tested for the presence of pesticide residues. Of these, $18 \%$ were found to violate maximum residue levels. Thus, the incidence of products from third world countries that do not meet statutory guidelines (EC) No. 396/2005 is approximately twice that of the average for foodstuffs from third world countries tested in other laboratories in Germany. In $10 \%$ of the non-compliant samples, the acute reference dose was exceeded by more than $100 \%$ and in a few by more than $1,000 \%$

Conclusions: As a result of the 3-year experience with the "bottleneck control" system at Frankfurt/Main Airport, the Hesse Ministry of Energy, Environment, Agriculture and Consumer Protection has voiced its opinion in the authorisation directive that mandatory prior notification is essential for all non-animal food products imported into the European Union. Only a unified Europe-wide approach can eventually lead to success.

\section{Background}

The globalisation of world commerce is a process that permanently alters the living conditions of all human beings. Here in Europe, we meet with the ramifications of these changes on a daily basis. These include the international exchange of goods. Evaluation of the European Rapid Alert System for Food and Feed shows that health safety problems which in recent years have become rare in Europe are more common when dealing with food products imported from third world countries. These include excessive levels of heavy metals, inadequate hygiene, unapproved veterinary pharmaceuticals in animal-derived foodstuffs or excessive levels of

\footnotetext{
* Correspondence: matthias.heinzler@lhl.hessen.de

+ Contributed equally

'Hesse State Laboratory, Druseltalstraße 67, 34131 Kassel, Germany

Full list of author information is available at the end of the article
}

pesticides in fruits and vegetables. The Veterinary Border Inspection Post Hesse (TGSH) was created in 1993 with the opening of the inner-European market. This was necessary in order to provide protection for living animals arriving at Frankfurt/Main Airport as well as to control infectious diseases of animals and importation of animal-derived foodstuffs. On 1 January 2005, the TGSH became Department V of the Hesse State Laboratory. Measured by the number of shipments of animal and plant products, the TGSH is one of the largest ports of entry in Europe. The Perishable Centre Frankfurt (PCF) is a 9,000- $\mathrm{m}^{2}$ interim refrigeration facility in which imported goods are stored before transport to their final destination.

The PCF serves as turnover facility for all perishable wares that arrive at the Frankfurt Airport by air freight or by surface transport. Department V.2 (Perishable

\section{SpringerOpen ${ }^{\circ}$}

(c) 2011 Heinzler et al; licensee Springer. This is an Open Access article distributed under the terms of the Creative Commons Attribution License (http://creativecommons.org/licenses/by/2.0), which permits unrestricted use, distribution, and reproduction in any medium, provided the original work is properly cited. 
Centre) of the TGSH is located there, and all testing of foods and food products that require refrigeration (fish, meat, fruit and vegetables) are performed there 365 days per year.

In April of 2007, the Hesse State Laboratory in close collaboration with the Hesse Ministry for the Environment, Energy, Agriculture and Consumer Protection began systematic testing of non-animal feed and food imported into the European Union (EU) from third world countries. A situation of this type results in a bottleneck which can be taken advantage of in order to obtain information about a very large volume of material utilising a very small number of samples. As first point of entry for numerous products from third world countries, the Frankfurt/Main airport constitutes just such a bottleneck.

This ability to monitor imports with the entire personnel and analytical capacity of the Hesse State Laboratory is a new approach in governmental health inspection. To the best of our knowledge, this is a unique situation, not just in Germany, but also Europe-wide.

\section{Results}

From April 2007 to December 2009, a total of 1,552 produce samples were tested for the presence of pesticide residues. All samples were tested by the QuEChERS method [1] developed by M. Anastassiades to detect the presence of 300 pesticides. The homogeneous and representative sub-sample is extracted in the frozen state by treatment with acetonitrile. After addition of magnesium sulphate, sodium chloride and citrate buffer, the mixture is shaken intensively and centrifuged for phase separation. An aliquot of the organic phase is cleaned by dispersive solid phase extraction employing bulk sorbents as well as $\mathrm{MgSO}_{4}$ for the removal of residual water. PSA-treated extracts are acidified by adding a small amount of formic acid to improve the storage stability of certain base-sensitive pesticides. The final extract can be directly employed for GC-MS- and LCMS-based determinative analysis.

In 127 of the samples, concentrations of dithiocarbamate and thiram disulfide fungicides were also determined using photometric methods [2]. Gas chromatographic detection of the antiparasitic drug Amitraz was carried out in an additional 63 samples [3].

A total of $18 \%$ of these samples were found to violate maximum residue levels according to regulation (EC) No. 396/2005 [4]. Even after allowing for an expanded measurement inaccuracy of $50 \%$, the concentration of pesticide residues exceeded the prevailing limits in 281 of the samples. In numerous cases, the measured residue concentrations exceeded the maximal permissible levels many times over.
The WHO defined the acute reference dose (ARfD) as "an estimate of the amount a substance in food or drinking water, normally expressed on a body weight basis, that can be ingested in a period of $24 \mathrm{~h}$ or less without appreciable health risks to the consumer on the basis of all known facts at the time of the evaluation" (JMPR, 2002). In $10 \%$ of the non-compliant samples, the ARfD was exceeded by more than $100 \%$ and in a few by more than $1,000 \%$.

The results of all pesticide analyses that have been performed are summarised in four figures. All of the non-compliant samples and their respective countries of origin have been summarised in Figure 1, presenting in a comprehensive and relatively simple manner the origin of all samples investigated together with their quotas of non-compliancy. This figure enables a quick and straightforward classification of problematic produce in relation to country of origin and contaminant. In this manner it is possible to successively characterise the food products that are contaminated with pesticides.

- Figure 1: Origin of all samples and quotas of noncompliance

- Figure 2: Food products that have been most frequently found to be non-compliant

- Figure 3: The most frequently found pesticides

- Figure 4: The pesticides that most often lead to objections.

All of the countries from which the 1,552 produce samples were derived are divided into four groups in Figure 1.

- Countries from which produce has not yet been examined (light colours)

- Countries with a low quota of non-compliant products $\geq 0 \%$ and $<5 \%$ (light grey): Chile, Ghana, Canada, Malaysia, Pakistan and Uganda

- Countries with a medium quota of non-compliant products $\geq 5 \%$ and $<20 \%$ (hatched): Egypt, Brazil, Jordan, Kenya, Peru, Sri Lanka, South Africa, Turkey and USA

- Countries with a high quota of non-compliant products $\geq 20 \%$ (dark grey): Dominican Republic, India, Israel, Colombia, Morocco, Thailand and Vietnam.

The samples with the highest rate of non-compliance ( $\geq 20 \%$ ) originated in the Dominican Republic, India, Israel, Colombia, Morocco, Thailand and Vietnam. Only those countries from which more than ten samples were examined were included in the figure.

The food products that were most frequently found to be non-compliant are arranged in groups in Figure 2. The categories with non-compliancy quotas over $30 \%$ were spices, squashes, exotic vegetables, physalis 


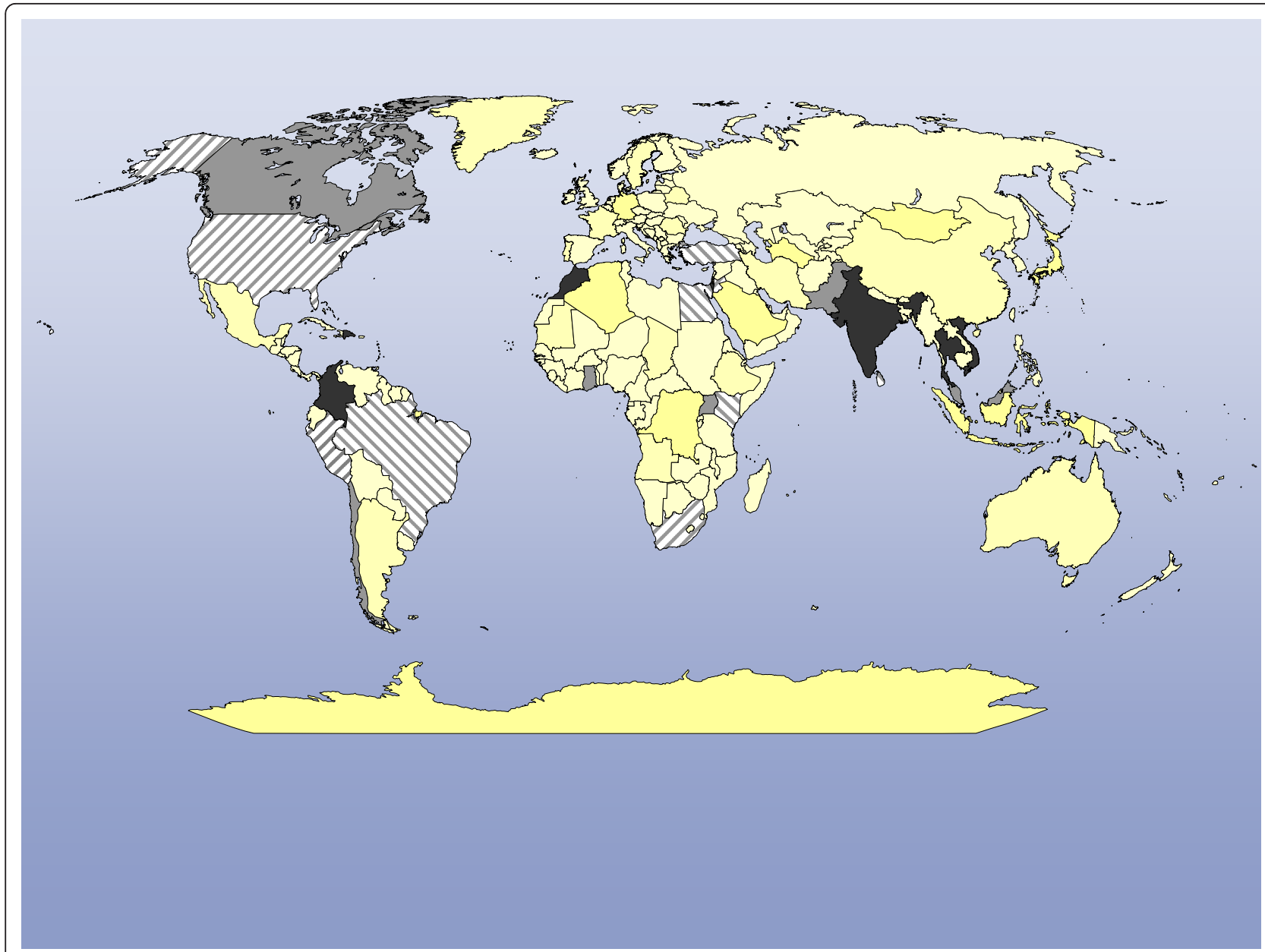

Figure 1 Origin of all samples and quotas of non-compliance. All of the countries from which the samples were derived are divided into four groups. a) Countries from which produce has not yet been examined (light colours) b) Countries with a low quota of non-compliant products $\geq 0 \%$ and $<5 \%$ (light grey): Chile, Ghana, Canada, Malaysia, Pakistan and Uganda c) Countries with a medium quota of non-compliant products $\geq 5 \%$ and $<20 \%$ (hatched): Egypt, Brazil, Jordan, Kenya, Peru, Sri Lanka, South Africa, Turkey and USA d) Countries with a high quota of non-compliant products $\geq 20 \%$ (dark grey): Dominican Republic, India, Israel, Colombia, Morocco, Thailand and Vietnam. Only those countries from which more than 10 samples were examined were included in the figure.

(cape gooseberries), basil, passion fruit and various fruiting vegetables. Only those food products are listed for which more than four samples were non-compliant.

In order to present an overview of the substances that are used worldwide, all of the pesticides that have been identified are presented in Figure 3. Pesticides that have been very frequently detected $(n>40)$ were carbendazim, imidacloprid, tebuconazole, azoxystrobin, cypermethrin, difenoconazole, dimethoate, methomyl, omethoate and methiocarb sulphoxide. All of the pesticides that were found in more than 25 samples are listed in Figure 3.

These results lead to the question of whether certain "pesticide/food product/country of origin combinations" are definable and therefore can be assigned to the group of products that, according to Annex I of the $\mathrm{VO}$ (EU) $669 / 2009$ [5], are subject to mandatory testing.
Figure 4 lists the six pesticides that were most frequently found to violate maximum pesticide residue levels. The three food products most at risk of noncompliance were shown to be aubergine from the Dominican Republic, okra from India and maracujas from Colombia.

A report from the food product and veterinary office of the European Public Health Alliance (DG SANCO) concerning an inspection tour in the Dominican Republic [6] clearly indicated that the local control system is, for the most part, deficient. "Agricultural pesticides are widely used and there is no effective control of administrative approval, marketing or use of these agents". It can be assumed that similar situations prevail in countries with similar non-compliance quotas (compare Figure 1). 


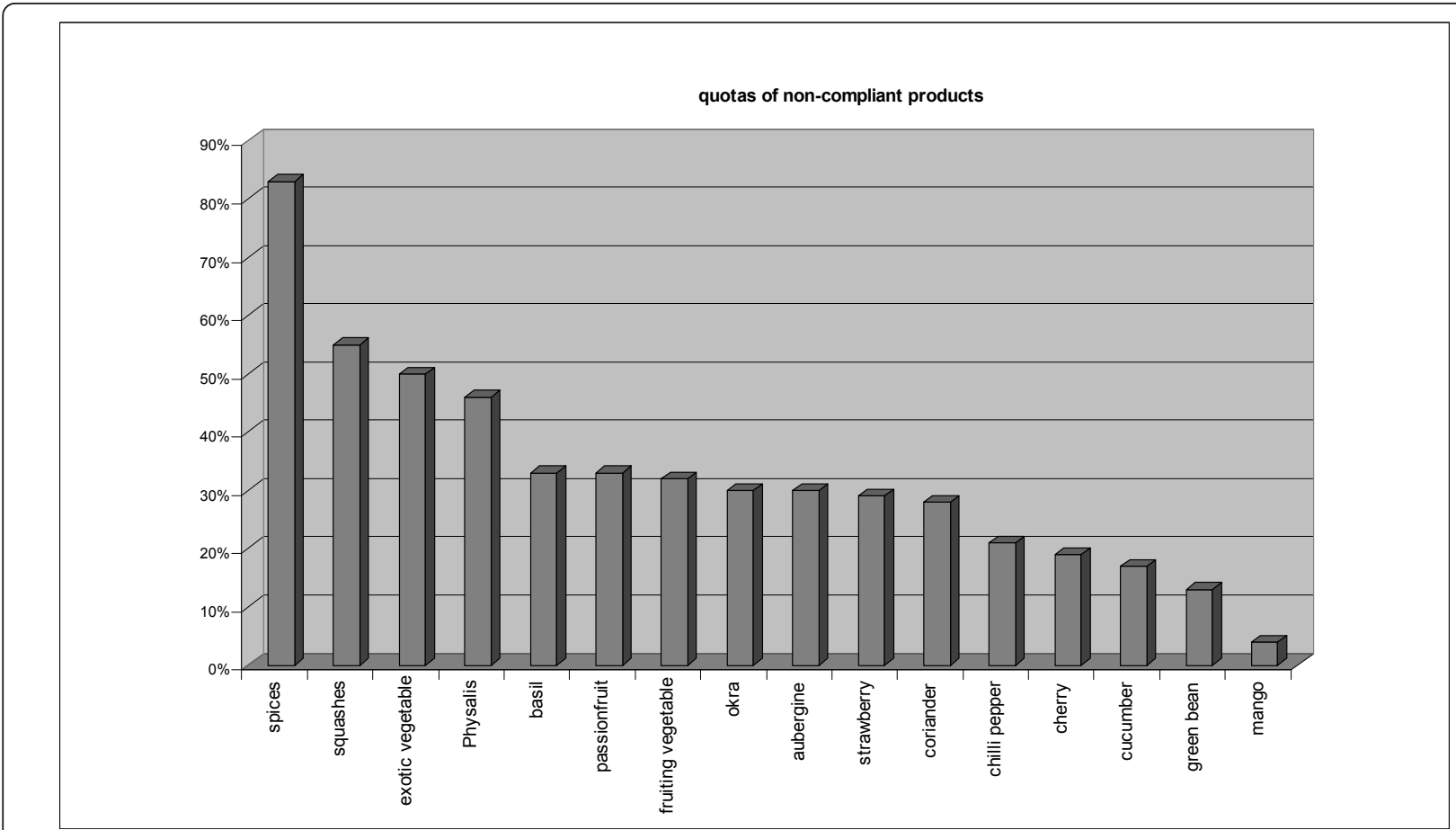

Figure 2 Quotas of non-compliant products. Summary of food products that were most frequently found to be non-compliant. a) Quota of non-compliancy > 30\%: spices, squashes, exotic vegetables, physalis (cape gooseberries), basil, passion fruit and various fruiting vegetables b) Non-compliancy quota > 20\% und < 30\%: okra, aubergine, strawberries and coriander c) Non-compliancy quota > 10\%: chilli, cucumber, cherry and green beans. Quotas of products for which more than four samples were non-compliant.

\section{Discussion}

\section{Experience with the "bottleneck" testing system}

Experience of the Hesse State Laboratory indicates that for products that violate maximal permissible levels of pesticide residues, approximately $35 \%$ of subsequent shipments will also be non-compliant. This observation confirms the suspicion of improper pesticide usage by the corresponding local producer. Since the importer is always required to present the bill of freight upon prior notification of consignment, the producer of origin is known, therefore allowing targeted testing.

According to Article $18 \mathrm{VO}$ (EC) 882/2004 [7] for cases in which maximum permissible levels of pesticides have been exceeded, no less than three subsequent shipments of the same product from the same producer of origin will be detained, i.e. an import permit for the EU will not be initially issued, based on suspicion of noncompliance. To gain release of the retained goods, the importer must verify the marketability of the goods by presenting test results from an accredited laboratory, obtained at his/her own cost.

If results are positive, i.e. levels exceeded maximal permissible limits of pesticides, risk-oriented sampling is carried out with regard to the type of product, country of origin and producer of origin. If negative results are obtained from three successive shipments, the following shipment may be imported without delay, whereby increased frequency of sampling of this type of product may still continue. Experience shows that if a type of product or a certain producer of origin has been noncompliant, subsequent shipments will often also be noncompliant. In such cases, the procedure of detaining at least three following shipments begins anew.

Following initial resentment by the importers, the system described above has in the meantime found a certain degree of acceptance. Some companies, however, try to avoid prior notification of consignment, which is voluntary for plant products. Therefore, during inspection rounds in the PCF, samples are also taken from products for which prior notification of consignment was not presented.

Among the positive experiences with this system, the first to be named would be the fact that importers put a good deal of pressure on their sources, i.e. their producers of origin, mainly because of reported non-compliance and in particular as a result of detained shipments. In addition, the cause is generally sought out at the level of the producer in order to avoid exceeding maximal concentrations of pesticides in future shipments.

A few cases to exemplify the experience with this programme:

- A Colombian producer reported that a worker forgot to note pesticide treatment in the books, and as a 


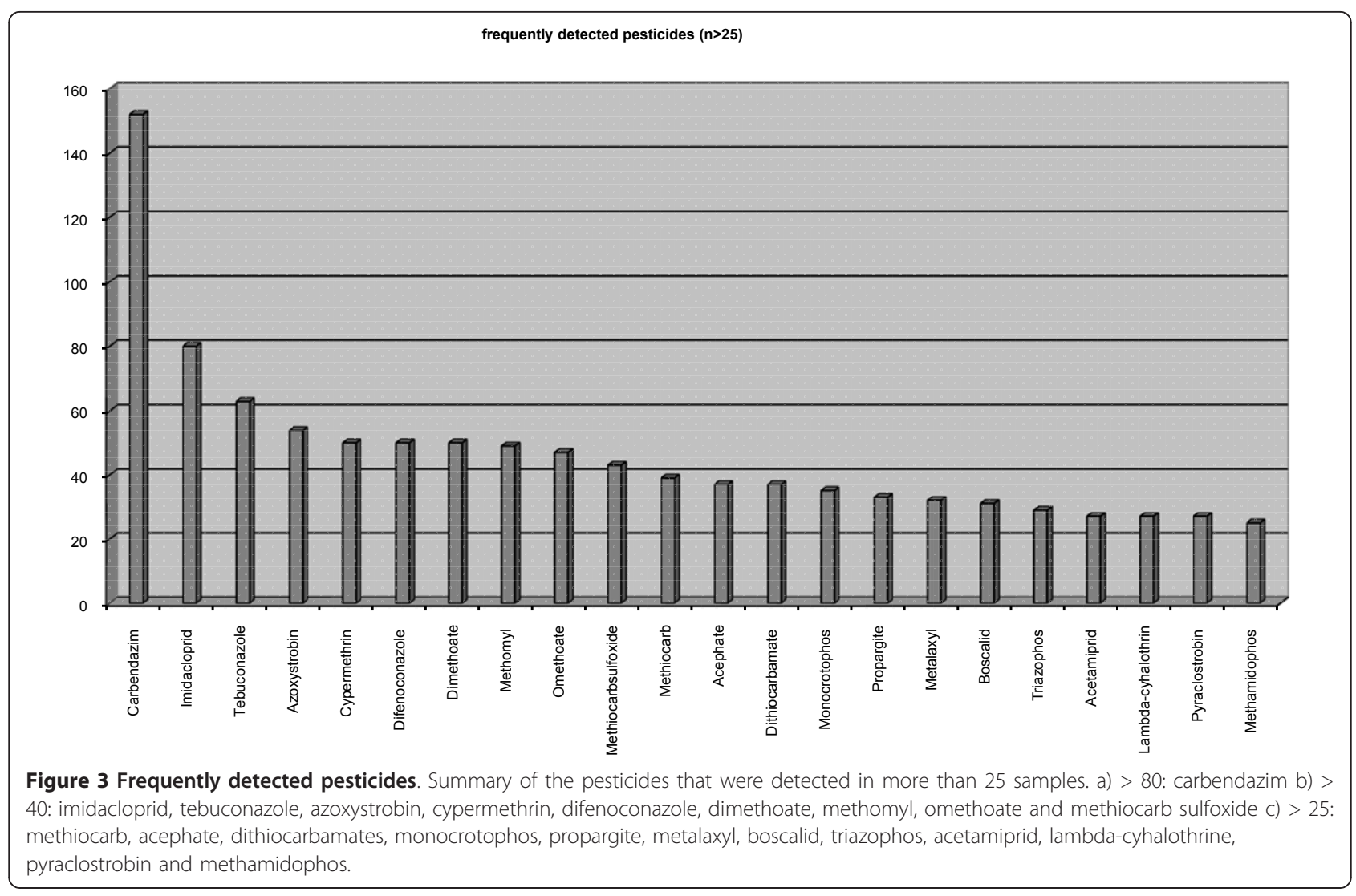

consequence, the prescribed withdrawal period was not maintained.

- Herb fields in Israel were contaminated with dinotefuran when adjoining flowerbeds were sprayed. The herb fields are now protected from wind carryover by 2m-high plastic shields.

- Pineapples from the Dominican Republic were treated by immersion with thiabendazole to avoid mould growth. This treatment was apparently performed inadvertently because it is normally reserved for pineapples that are shipped by sea. Since these pineapples were shipped by air, however, the shipping time was inadequate for degradation of the fungicidal agent.

- Importers have begun cancelling orders, i.e. changing their sources (producers of origin).

- There has been an increase in requests for pesticide analyses in German laboratories.

\begin{tabular}{|lcll|}
\hline Pesticide & $\begin{array}{c}\text { number of } \\
\text { non- } \\
\text { compliant } \\
\text { samples }\end{array}$ & type & comments \\
Methiocarb & 37 & Insecticide & $\begin{array}{l}\text { Found exclusively in food products from the } \\
\text { Dominican Republic, primarily in aubergines }\end{array}$ \\
Carbendazim & 36 & Fungicide & Diverse countries, diverse products \\
Acephate & 33 & Insecticide & $70 \%$ in okra pods from India \\
Monocrotophos & 30 & Insecticide & $60 \%$ in maracujas from Colombia \\
Triazophos & 23 & Insecticide & $96 \%$ in okra pods from India \\
Tebuconazole & 23 & Fungicide & Diverse countries, diverse products \\
Figure 4 Pesticides that were most frequently found to violate maximum residue levels. Six pesticides that were most frequently found to \\
violate maximum pesticide residue levels.
\end{tabular}


- There has also been an increase in pesticide analyses in the countries of origin, albeit with extremely variable results. Therefore, considerable effort has been undertaken to develop local analytical laboratories capable of delivering sustainable results that are accepted by German authorities.

\section{Government sanctions imposed as a result of the "bottleneck control"}

In a number of cases, import firms with a history of non-compliance have been required to present their products for examination: all following shipments of the same product and from the same producer of origin must be presented to the TGSH for examination before they can enter the EU marketplace.

In addition, strict requirements for inspection have been imposed by enforcement authorities: Shipments of especially heavily contaminated types of products from specific countries of origin must be inspected at the cost of the importer before they can be placed on the open market. During spot checks, test results for every shipment must be then submitted to the government authorities; otherwise, predefined monetary penalty payments immediately fall due.

\section{Conclusions}

In October 2008, the Food and Veterinary Office of the EU paid an inspection visit to Hesse, Germany in order to evaluate the system for governmental control of pesticide residues. The evaluation in the closing report [8]"The Competent Authority of Hesse carry out well organised and risk based regular official controls on food and feed of non-animal origin imported into the EU through the Border Inspection Point at Frankfurt Airport, as required by Article 15 of Regulation (EC) No 882/2004" indicates that the concept of "bottleneck control" is a step in the right direction.

The large number (approximately 20\%) of rejections based on non-compliance of pesticide residue levels also supports the concept of "bottleneck control" with risk based sampling. Without mandatory prior notification of consignment, however, it is virtually impossible to assure a systematic sampling according to the risk assessment. This was already noted in the previously mentioned DG SANCO report. The amending Decision to Article 15 of Regulation 882/2004, published as Commission Regulation VO (EC) 669/2009 in August in the official journal of the EU, presents plans for mandatory prior notification of consignments, however, only for the feed and food listed in Annex I.

As a result of the 3-year experience with the "bottleneck control" system at the Frankfurt Airport, the Hesse Ministry of Energy, Environment, Agriculture and Consumer Protection has voiced its opinion in the authorisation directive that mandatory prior notification is essential for all non-animal food products imported into the EU. Only a unified Europe-wide approach can eventually lead to success. This would bring us considerably closer to our goal of consumer protection that begins at the outer borders of Europe.

\section{Author details}

${ }^{1}$ Hesse State Laboratory, Druseltalstraße 67, 34131 Kassel, Germany ${ }^{2}$ Hesse State Laboratory, Frankfurt Airport, Perishable Center Building 454, 60549 Frankfurt/Main, Germany ${ }^{3}$ Hesse State Laboratory, Schubertstraße 60, 35392 Gießen, Germany

\section{Authors' contributions}

$\mathrm{MH}$ carried out the analysis of pesticides and drafted the manuscript. DG was responsible for the official controls on food and feed of non-animal origin at Frankfurt/Main airport. HB conceived the study and participated in its design. All authors read and approved the final manuscript.

\section{Competing interests}

The authors declare that they have no competing interests.

Received: 12 November 2010 Accepted: 18 March 2011

Published: 18 March 2011

\section{References}

1. Amtliche Sammlung von Untersuchungsverfahren nach § 64 LFGB: Multimethode zur Bestimmung von Pflanzenschutzmittelrückständen in pflanzlichen Lebensmitteln mittels GC-MS(/MS) oder LC-MS/MS nach Acetonitril-Extraktion/Verteilung und Aufreinigung mittels dispersiver SPE (QuEChERS).

2. Amtliche Sammlung von Untersuchungsverfahren nach § 64 LFGB: Bestimmung von Dithiocarbamat- und Thiuramdisulfid-Rückständen, Teil 3: UV-Spektralphotometrisches Xanthogenat-Verfahren.

3. Amtliche Sammlung von Untersuchungsverfahren nach § 64 LFGB: Gaschromatographische Bestimmung von Amitraz und Vinclozolin sowie ihren 2,4-Dimethylanilin bzw. 3,5-Dichloranilin enthaltenden Metaboliten in Lebensmitteln.

4. Brussels; 2005, 1-16, Regulation (EC) No 396/2005 of the European Parliament and of the Council of 23 February 2005 on maximum residue levels of pesticides in or on food and feed of plant and animal origin and amending Council Directive 91/414/EEC. Official Journal of the European Union L70, 16.3.2005.

5. Commission Regulation (EC) No 669/2009 of 24 July 2009 implementing Regulation (EC) No 882/2004 of the European Parliament and of the Council as regards the increased level of official controls on imports of certain feed and food of non-animal origin and amending Decision 2006/504/EC Brussels; 2009, 11-21, Official Journal of the European Union L194, 25.7.2009.

6. European Public Health Alliance: DG SANCO/7848/2008: Excerpt of the report from the Food and Veterinary Authority on the inspection of facilities in the Dominican Republic 3rd-12th June 2008 Brussels; 2008.

7. Regulation (EC) No 882/2004 of the European Parliament and of the Council of 29 April 2004 on official controls performed to ensure the verification of compliance with feed and food law, animal health and animal welfare rules Brussels; 2004, 1-141, Official Journal of the European Union L165, 30.4.2004.

8. Food and Veterinary Office Annual Report 2008. [http://ec.europa.eu/ food/fvo/annualreports/ann_rep_2008_en.pdf].

doi:10.1186/2190-4715-23-14

Cite this article as: Heinzler et al:: New border control system for food originating from third world countries. Environmental Sciences Europe 2011 23:14. 